\title{
Perceptions of Traumatic Brain Injury among Public Defenders in the State of Minnesota
}

\author{
Jerrod Brown ${ }^{1-3^{*}}$ and Jeffrey $P$ Louie ${ }^{4}$ \\ ${ }^{1}$ Concordia University, St. Paul, MN, USA \\ ${ }^{2}$ Pathways Counseling Center, St. Paul, MN, USA \\ ${ }^{3}$ The American Institute for the Advancement of Forensic Studies, St. Paul, MN, USA \\ ${ }^{4}$ University of Minnesota, Department of Pediatrics, Minneapolis, MN, USA
}

*Corresponding author: Jerrod Brown, Ph.D., MA, MS, MS, MS, Pathways Counseling Center, 1919 University Ave. W. Suite 6 St. Paul, Minnesota 55104, USA, Tel: 651-734-5517; E-mail: jerrod01234brown@live.com

Received date: June 21, 2017; Accepted date: July 03, 2017; Published date: July 07, 2017

Copyright: @ 2017 Brown J. This is an open-access article distributed under the terms of the Creative Commons Attribution License, which permits unrestricted use, distribution, and reproduction in any medium, provided the original author and source are credited.

\begin{abstract}
Traumatic brain injury (TBI) occurs when an external blow to the head causes a disruption in the normal functioning of the brain. Injuries such as these not only increase the risk of involvement with the criminal justice system for the individual, but also may make it more difficult to navigate within the legal system. Unfortunately, public defenders may not be familiar with the challenges of TBI their clients face. The aim of this study is to explore the familiarity of public defenders with the signs and symptoms of TBI. Additionally, the study investigates the degree to which public defenders recognize the prevalence and impacts of TBI in the legal system. The study consisted of a 14-item electronic survey distributed to all public defenders in Minnesota. Results found that public defenders varied widely in their familiarity with TBl's symptoms, prevalence, and impacts in the legal system. Although the majority of respondents had not received any advanced training on TBI, most believed such training would be beneficial for their clients. This study clearly shows a need for more training on cognitive, memory, and behavioural impairments experienced by defendants who have been impacted by TBI.
\end{abstract}

Keywords: Traumatic brain injury; Legal; Miranda rights; Competency to stand trial; Public defenders; Screening; Training

\section{Introduction}

A traumatic brain injury (TBI) occurs when an external force, including but not limited to a blow to the head, causes a disruption in the normal functioning of the brain [1-4]. Although the effects of the disruption in brain functioning can vary widely across individuals, symptoms may include intellectual impairments, executive control deficits (information processing speed), short- and long-term memory alterations, affective dysregulation (mood disorders), issues with adaptive functioning (e.g., decision making and problem solving), anxiety, psychosis, impulsivity, irresponsibility, and behavioral problems [5-10]. Despite this array of potential symptoms, TBI is often considered a "hidden" or "invisible" injury because these symptoms are more difficult to identify than a bruise or broken bone [11,12].

Because TBI is likely under-diagnosed across a wide variety of settings, current prevalence estimates likely underestimate the number of people who suffer from TBI [13]. That said, TBI has an estimated prevalence rate of $1.1 \%$ to $1.7 \%$ in the general population [14]. This prevalence only increases in medical settings, where TBI-related hospitalization increased by $11 \%$ from 2001 to 2010 and TBI-related emergency room visits increased by $70 \%$ [15]. Another area where TBI is likely over-represented is the criminal justice system [16]. One study estimated that TBI is present in approximately $64 \%$ of male and $70 \%$ of female adult offenders [17]. Other research suggests that somewhere between $25 \%$ and $87 \%$ of the more than two million offenders in U.S. jails and prisons have sustained at least one TBI during their lifetime [18-23]. This wide variation in prevalence estimates may be a function of the assessment protocol employed in a given study. For example, Diamond et al. [20] reported approximately $1 \%$ of prisoners had a history of TBI based on an intake interview whereas $83 \%$ of prisoners had a history of TBI based on a detailed screening instrument. Unfortunately, an estimated 45\% [19] and 61\% [20] of offenders with TBI do not receive adequate medical treatment for this ailment.

A lack of sufficient treatment can result in TBI contributing to a wide range of problems in offenders. From an early age, TBI can result in cognitive impairments that contribute to the onset of antisocial behaviours [24]. This includes cases where the onset of TBI preceded contact with the criminal justice system [25]. Along with antisocial behavior including violence, TBI often co-occurs with academic problems in adolescence. In adult offenders, the presence of TBIs where consciousness was lost or multiple TBI events increased the likelihood of major depression [22]. Further, TBI where consciousness was lost in the previous year increased the risk for psychosis in prisoners [22]. As these findings highlight, early detection of TBI is important in the prevention of antisocial behavior and mental illness.

In addition to these deleterious outcomes, TBI has a negative impact on defendants attempting to navigate the criminal justice system. This could take the form of a suspect making ill informed decisions by waiving legal rights such as Miranda or the right to an attorney. Alternatively, TBI could limit a defendant's competency to stand trial. For example, TBI may result in communication and memory impairments that make it difficult to communicate effectively with one's attorney. As a result, the defendant may not be able to effectively assist his or her attorney in the development of their legal strategy. Nonetheless, there is limited research on how TBI impacts defendants navigating the various stages of the legal system. 
In light of the number of individuals in the criminal justice system with TBI, and the varied impacts of TBI during the legal process, public defenders must be aware of TBI. However, there is limited information on the experiences and knowledge base of public defenders representing defendants with TBI in a court of law. To our knowledge, few public defenders receive training focused on the recognition and understanding of TBI. As a result, public defenders have limited knowledge about the prevalence of TBI-related deficits among their clients or the ranging impacts of these deficits across different settings. This likely extends to judges, parole officers, probation officers, and others who often have not received the appropriate training to recognize and accommodate the needs of individuals impacted by a TBI. As such, legal professionals are in dire need of training on the symptoms of TBI. Increased knowledge of TBI could make a world of difference in assisting defendants with this disorder. Further, public defenders could help improve the identification of defendants with TBI.

The accurate identification and early referral to a qualified mental health professional provides the best chance of successful remediation and treatment for the defendant. Being attuned to the special needs and accommodations of those with TBI may also make for a more comprehensive defense throughout the legal process. The best way to ensure that due process rights are protected for all defendants, including those with TBI, is to understand the unique characteristics of TBI and make all reasonable accommodations under the law.

\section{The Present Study}

Individuals with TBI are disproportionately likely to become involved in the U.S. criminal justice system [17]. Once entangled in this system, individuals with TBI frequently encounter challenges and difficulties as a function of the cognitive, adaptive, and behavioral symptoms of TBI. To limit these challenges and difficulties, professionals working in the criminal justice system, such as lawyers and judges, must be able to recognize the possible presence of TBI and ensure these individuals receive the necessary services and treatment. Unfortunately, it is unclear if legal professionals are familiar enough with TBI to meet these obligations. In particular, there is a lack of research on the TBI-related knowledge of public defenders, which are a first-line of defence in ensuring the adequate treatment of their clients. To this end, this study involved conducting a web-based survey of open- and closed-ended questions in a sample of public defenders.

This study had two aims. First, we explore the familiarity of public defenders with the signs and symptoms of TBI. We hypothesize that the majority of public defenders will not be able to accurately identify the symptoms and warning signs of TBI. Second, we investigate the degree that public defenders recognize the prevalence and impacts of TBI in the legal system. We expect that public defenders will be generally unfamiliar with the prevalence of TBI along with the consequences that cognitive, adaptive, and behavioral impairments have in the legal system. Overall, we anticipate finding that public defenders could greatly benefit from advanced education and training on TBI in the legal system.

\section{Method}

A survey request email, with URL, was sent to public defenders at the State of Minnesota Board of Public Defense. The University of Minnesota Institutional Review Board (IRB) approved this study. Each participant provided informed consent by completing at least a portion of the survey. The survey was developed by the primary study authors based on their professional clinical experience and a review of the pertinent literature. The web-based survey was built using Google Forms to collect and record responses in a Google Sheets document linked to the survey. After the initial survey recruitment email, weekly reminders were sent for a one-month period.

The survey included 14 items. Four questions focused on demographic characteristics: gender, age, years spent practicing law, and county where most of the respondent's cases occur. Ten questions inquired about TBI. This mostly consisted of closed-ended questions on assessing different levels (mild, moderate, or severe) of TBI. All data was analysed using SPSS 22.

A traumatic brain injury (TBI) occurs when an external force, including but not limited to a blow to the head, causes a disruption in the normal functioning of the brain (5). Although the effects of the disruption in brain functioning can vary widely across individuals, symptoms may include intellectual impairments, executive control deficits (e.g., information processing speed), short- and long-term memory alterations, affective dysregulation (e.g., mood disorders), issues with adaptive functioning (e.g., decision making and problem solving), anxiety, psychosis, impulsivity, irresponsibility, and behavioral problems. Traumatic brain injury can result from physical blunt force trauma, piercing of the skull, or through shockwaves transmitted through the skull as a result of sudden acceleration or deceleration such as a car crash or sports collision. As the soft pliable material of the brain impacts and bounces within the skull cavity it can cause bruising and damage affecting smell, sight, hearing, taste, and balance. These symptoms may be permanent or can heal after days, weeks, or even years as the nerves repair the damage and reactivate the sensory receptors [26].

\section{Results}

The results listed here were gathered to establish a baseline of understanding among public defenders in Minnesota. There is no "correct" answer, and no comparison to other published studies on the prevalence of awareness of TBI symptoms among public defenders was made.

A total of 612 online survey email requests were sent to all assistant public defenders within the state of Minnesota. All participants contacted were aged 18 or over. Of those survey's, 171 were at least partially completed rendering a return rate of approximately $28 \%$. Respondents on the variable of gender $(n=165)$ consisted of 91 females (55\%), 73 males (44\%), and 1 other ( $0.61 \%)$. Respondents on location $(\mathrm{n}=171)$, were mostly from outside Hennepin and Ramsey counties $(68 \%$; $n=117)$, with only $32 \%$ of respondents $(n=54)$ from Hennepin and Ramsey counties. On the topic of experience $(n=168)$, the largest group (33\%) had been public defenders for less than 5 years. Finally, respondents $(n=165)$ typically felt training should occur every year $(53 \% ; n=87)$ or at least every 5 years $(40 \% ; n=66)$ (Table 1$)$.

\begin{tabular}{|l|l|l|}
\hline Domain & Subdomain & $\mathbf{n}(\%)$ \\
\hline \multirow{3}{*}{ Years as Public Defender $(n=168)$} & Less than 5 years & $56(33.33 \%)$ \\
\cline { 2 - 3 } & $5-10$ years & $23(13.69 \%)$ \\
\cline { 2 - 3 } & $10-15$ years & $24(14.29 \%)$ \\
\cline { 2 - 3 } & $15-25$ years & $40(23.81 \%)$ \\
\hline
\end{tabular}


Citation: Brown J, Louie JP (2017) Perceptions of Traumatic Brain Injury among Public Defenders in the State of Minnesota . J Forensic Res 8:

Page 3 of 6

\begin{tabular}{|l|l|l|}
\hline & $25+$ years & $25(14.88 \%)$ \\
\hline \multirow{4}{*}{ Gender $(\mathrm{n}=165)$} & Female & $91(55.15 \%)$ \\
\cline { 2 - 3 } & Male & $73(44.24 \%)$ \\
\cline { 2 - 3 } & Other & $1(0.61 \%)$ \\
\hline \multirow{3}{*}{ County $(\mathrm{n}=171)$} & In Ram/Hen & $54(31.58 \%)$ \\
\cline { 2 - 3 } & Other Country & $117(68.42 \%)$ \\
\hline \multirow{5}{*}{ Desired Training Frequency $(\mathrm{n}=165)$} & Not at All & $6(3.64 \%)$ \\
\cline { 2 - 3 } & Every 6 months & $5(3.03 \%)$ \\
\cline { 2 - 3 } & Every Year & $87(52.73 \%)$ \\
\cline { 2 - 3 } & Every 5 years & $66(40 \%)$ \\
\cline { 2 - 3 } & Every 10 years & $1(0.61 \%)$ \\
\hline
\end{tabular}

Table 1: Respondent characteristics.

\section{Familiarity of public defenders with TBI}

To explore the familiarity of public defenders with the signs and symptoms of TBI, the respondents were asked to describe, based on their own opinion and experiences, the mild and moderate symptoms of TBI from a list of 11 choices. The choices were not mutually exclusive. Participants were asked to simply choose all that apply. As shown below in Table 2, the most commonly selected symptom for the mild option was "headache" (88\%). This symptom was followed closely by "depression" (74\%), "visual problems" (67\%), "balance problems" (66\%), "aggression" (57\%), and "hearing problems" (56\%). Other symptoms with lower rates of endorsement included "manic-like behavior" (41\%), "seizures" (35\%), "suicide ideation" (27\%), shortness of breath (22\%), and hiccups (16\%). Approximately $45 \%$ of the respondents selected $3(13 \%), 4(14 \%)$, or 5 symptoms (18\%). Interestingly, $9 \%$ of the time participants selected all 11 symptoms. All other symptom counts $(0,1,2,6,7,8,9$, and 10$)$ represented less than $8 \%$ each.

\begin{tabular}{|l|l|l|}
\hline Domain & Subdomain & $\mathbf{n}(\mathbf{\%})$ \\
\hline \multirow{5}{*}{ Mild Symptoms $(\mathrm{n}=171)$} & Headache & $151(88.30 \%)$ \\
\cline { 2 - 3 } & Depression & $127(74.27 \%)$ \\
\cline { 2 - 3 } & Visual Problems & $114(67.25 \%)$ \\
\cline { 2 - 3 } & Balance Problems & $112(66.08 \%)$ \\
\cline { 2 - 3 } & Aggression & $97(57.31 \%)$ \\
\cline { 2 - 3 } & Hearing Problems & $95(55.56 \%)$ \\
\cline { 2 - 3 } & Manic-like Problems & $69(40.94 \%)$ \\
\hline & Seizures & $58(34.50 \%)$ \\
\hline & Suicide Problems & $46(27.49 \%)$ \\
\hline & Shortness of Breath & $37(22.22 \%)$ \\
\hline & Hiccups & $26(15.79 \%)$ \\
\hline
\end{tabular}

Table 2: Mild TBI signs and symptom as identified by respondents.

In contrast, the most commonly selected symptom for moderate was "difficulty concentrating or completing tasks" (91\%). This was followed closely by "mood-swings" (83\%), "depression" (81\%), "headache" (80\%), 'the sense you just don't feel like yourself" (79\%), "dizziness" (78\%), "suicidal ideation" (68\%), and "giddiness" (45\%). In stark contrast to the results of the mild symptoms, the number of symptoms most often selected for the moderate group was 6 (15\%), 7 $(18 \%)$, or $8(36 \%)$. Also, in contrast to the mild symptoms counts, the options of 0 through 3 only combined to account for $10.5 \%$ responses (Table 3).

\begin{tabular}{|l|l|l|}
\hline Domain & Subdomain & $\mathbf{n}(\%)$ \\
\hline \multirow{4}{*}{$\begin{array}{l}\text { Moderate to Severe } \\
\text { Symptoms (n=171) }\end{array}$} & Difficulty Concentrating & $155(91.23 \%)$ \\
\cline { 2 - 3 } & Mood Swings & $141(83.04 \%)$ \\
\cline { 2 - 3 } & Depression & $138(80.70 \%)$ \\
\cline { 2 - 3 } & Deadache & $137(80.12 \%)$ \\
\cline { 2 - 3 } & Dizziness & $135(78.95 \%)$ \\
\cline { 2 - 3 } & Suicidal Ideation & $133(78.36 \%)$ \\
\cline { 2 - 3 } & Giddiness & $116(68.42 \%)$ \\
\hline
\end{tabular}

Table 3: Moderate TBI signs and symptom as identified by respondents.

\section{Recognition of TBI's Impact in criminal justice system}

To gauge the respondents' familiarity with TBI's impact in the criminal justice system, the survey asked several questions about TBI. This included requesting the participants to estimate the prevalence of TBI among the defendants that they have represented in court. Of 166 respondents, the largest group estimated between $11 \%-25 \%$ (37\%), followed by $26 \%-50 \%$ (27\%), $0 \%-10 \%$ (17\%), $51 \%-75 \%$ (16\%), and 76\%-100\% (2\%) (Table 4).

\begin{tabular}{|l|l|l|}
\hline Domain & Subdomain & $\mathbf{n}(\mathbf{\%})$ \\
\hline \multirow{2}{*}{$\begin{array}{l}\text { Percent Clients Involved in Criminal Activity } \\
(n=166)\end{array}$} & 0 to $10 \%$ & $\begin{array}{l}29 \\
(17.47 \%)\end{array}$ \\
\cline { 2 - 3 } & $11 \%$ to $25 \%$ & $\begin{array}{l}62 \\
(37.35 \%)\end{array}$ \\
\cline { 2 - 3 } & $26 \%$ to $50 \%$ & $\begin{array}{l}45 \\
(27.11 \%)\end{array}$ \\
\cline { 2 - 3 } & $51 \%$ to $75 \%$ & $\begin{array}{l}26 \\
(15.66 \%)\end{array}$ \\
\cline { 2 - 3 } & $76 \%-100 \%$ & $4(2.41 \%)$ \\
\hline
\end{tabular}

Table 4: Estimated prevalence of TBI among defendants.

Participants were also asked how often they referred defendants with a confirmed diagnosis of TBI to dispositional advisers in a typical month. Of the respondents to this question $(n=168), 62 \%$ did not typically make a referral. This was followed by $35 \%$ of respondents making 1-2 referrals per month and 3\% of respondents making 3-4 referrals per month. Similarly, participants were asked in a typical month how often they referred clients with a suspected diagnosis of 
Page 4 of 6

TBI to dispositional advisers. Of the respondents to this question $(\mathrm{n}=167), 65 \%$ did not refer at all. Additionally, 31\% of respondents made 1-2 referrals per month, $4 \%$ made 3-4 referrals per month, and less than $1 \%$ made $5-10$ referrals per month (Table 5).

\begin{tabular}{|l|l|l|}
\hline Domain & Subdomain & $\mathbf{n}(\%)$ \\
\hline \multirow{3}{*}{ Suspected TBI Referrals ( $\mathrm{n}=167)$} & $1-2$ month & $\begin{array}{l}51 \\
(30.54 \%)\end{array}$ \\
\cline { 2 - 3 } & $3-4$ month & $6(3.59 \%)$ \\
\cline { 2 - 3 } & $5-10$ month & $1(0.6 \%)$ \\
\cline { 2 - 3 } & None & $\begin{array}{l}109 \\
(65.27 \%)\end{array}$ \\
\hline
\end{tabular}

Table 5: Referral of suspected diagnosis of TBI to dispositional advisers.

Finally, we explored the topic of advanced education and training on TBI in the legal system. Of the respondents $(n=168)$, the vast majority $(73 \%)$ reported never receiving relevant training in this area. The rest of the respondents had received some training (18\%) or were unsure or didn't know (9\%). When participants were asked about when training took place $(\mathrm{n}=159)$, if at all, most never had any $(70 \%)$ or could not recall (10\%). This was followed by less than 5 years $(9 \%)$, 5-10 years (5\%), within 12 months (4\%), and more than 10 years (1\%). Among participants that received training on the recognition of TBI $(n=53)$, a follow-up question on the helpfulness of training was asked. The largest percentage of participants found the training "somewhat helpful" (42\%), "helpful" (34\%), "very helpful" (13\%), "not helpful" $(8 \%)$, and "extremely" (4\%). Lastly, participants $(n=166)$ were asked if they felt a TBI screening tool would be help them screen more defendants. The majority of respondents replied "yes" (70\%), followed by "I do not know" (25\%) and "no" (5\%).

\section{Discussion}

Prevalence rates for TBI in excess of $60 \%$ have been found in a meta-analysis of adult offenders [17]. Similarly, the prevalence rate of traumatic incidents, including but not limited to TBI, is estimated to be at or near $60 \%$ in adult offenders, with roughly half that rate observed in juvenile offenders [24,27]. In this study, when asking public defenders to estimate the percentage of their clients with TBI, over $81 \%$ of the respondents underestimated the actual TBI prevalence. With such high prevalence rates, it is likely that public defenders come into contact with defendants with TBI on a fairly frequent basis.

Despite this high prevalence, TBI-focused training remains an area of concern for public defenders. Almost $75 \%$ of respondents reported receiving no training on the mental, memory, or behavioral impairments experienced by clients with TBI. Of the limited number of public defenders who did receive TBI-focused training, most (87\%) found the training at least somewhat helpful to very helpful. These findings emphasize how helpful training can be in this context. Because individuals with TBI can confabulate in the form of false confession and false testimony, recognition and remediation prior to the conviction of an innocent person is in the interests of all parties concerned.

When asked to identify signs and symptoms of a mild and moderate TBI, the majority of respondents correctly chose the most common symptom of headache and depression. However, incorrect choices of seizures (35\%), hiccups (16\%), and shortness of breath (23\%) were also selected. The heterogeneity of responses is highly suggestive of the need for education. In addition, coupled with increasing awareness of TBI should be the ability to refer to TBI specialists.

This survey showed that over $60 \%$ of respondents never referred either known or suspected cases of TBI to dispositional advisers. This highlights the need for improvements to awareness and training for public defenders in the area of TBI. As a result, this should increase referrals of defendants with suspected or confirmed TBI to dispositional advisors.

With these figures in mind, $70 \%$ of respondents felt a screening app or tool would be helpful in their work. Other research reinforces this finding with routine screening for the presence of TBI by a qualified forensic psychologist or psychiatrists is strongly encouraged [28]. Awareness through a screening app or training should increase desired outcomes of defendants with TBI in various criminal justice and legal settings. Using both or one modality would, likely increase referral to of defendants with suspected or confirmed TBI dispositional advisors.

The researchers believe that with increased awareness and understanding by public defenders and other court personnel more referrals to qualified professionals will result. Under the guidance of these professionals appropriate treatment, sentencing, and rehabilitation are all likely to have increased probability for success resulting in better outcomes for all stakeholders involved. This would be another avenue for future investigation.

\section{Limitations}

The present survey was limited by a modest response rate of $28 \%$ (n $=612$ ). Although this sample may be sufficient for generalizing results, it is unclear if these findings will generalize to other professional groups or other states. Further, this study was limited to public defenders and did not include judges, correctional officers, and parole/ probation officers. Finally, respondents were only drawn from the state of Minnesota. As such, these findings are presented as a preliminary study for future research in a larger scope. Future research should explore if these findings generalize in other legal professionals and outside of Minnesota. The present survey could serve as a template for such research with minor modifications.

\section{Implications}

This study has three important implications. First, there was wide variation in the degree that public defenders were able to successfully distinguish the common symptoms of TBI. As such, public defenders would likely benefit from a standard educational handout, which should incorporate a straightforward description of TBI's prevalence in general and criminal justice populations along with a discussion of how TBI impacts Miranda rights, competency to stand trial, and the likelihood of re-arrest. The importance of this endeavor is emphasized by the fact that public defenders are often unfamiliar with this information as it relates to TBI. This standard educational handout may be most effective as just one aspect of a broader attempt to conduct and translate research into practice and policy. Central among these efforts should be the development of purpose-built forensic screening instruments for TBI.

Second, public defenders are frequently unaware of the psycholegal impairments resulting from TBI-related deficits. In this context psycholegal impairments are psychological impairments that impact a 
defendant's ability to successfully navigate the criminal justice process [29]. Such impairments can include affective dysregulation (e.g., mood disorders), anxiety, psychosis, impulsivity, and behavioral problems [4-10]. To address this, the development of an annotated bibliography of research studies in this area could assist in the education of these legal professionals.

Third, public defenders felt the need for training in the area of TBI. To this end, the development of additional training resources and continuing education programs focused on the impacts of TBI in the legal system are essential. Increased familiarity with TBI will not only help improve the identification of defendants with TBI, but also help better understand the defendant's deficits and limitations. Ultimately, accurate diagnosis and appropriate treatment offer the best chance of successful reintegration into the community.

\section{Suggestions for Future Research}

The current study is ripe for expansion across multiple domains. Foremost, this study should be replicated with both public defenders and prosecutors in the federal system and in jurisdictions across the U.S. and in other nations. Of particular interest, a survey that targets forensic evaluators charged with psychologically evaluating defendants holds a great deal of promise. Forensic evaluators are a critical population because of the multifaceted role that they play in evaluating the defendant and providing testimony in court about their evaluation. Expansion to fields outside the courtroom including corrections, parole, and probation may provide previously undiscovered insights into understanding of TBI. Along the same lines, surveying treatment professionals working in contexts ranging from detox centers and forensic hospitals to outpatient substance use and mental health treatment settings could be informative. Similarly, applying the survey to caregivers, immediate family members, and relatives of the defendant could yield insightful results. Perhaps the most important direction remains directly surveying individuals with TBI who have been involved in the criminal justice system. Throughout these surveys, questions should be added to better understand the impacts of TBI on competency to stand trial, ability to make legal decisions like waiver of Miranda rights, and provide testimony in spite of the possibility of confabulation and suggestibility. Such work is central to determining if there are professional, regional, or cultural differences in the understanding of TBI and its associated deficits. The primary goal of future studies should be aimed at not just determining what criminal justice, forensic mental health, and legal professionals know about TBI, but what these professionals need to do to modify their approaches to be more effective when interacting and communicating with individuals impacted by TBI. This should lead to an increase in positive long-term outcomes for all involved parties.

\section{Conclusion}

This study clearly establishes the need for more training of public defenders on the cognitive and behavioral impairments experienced by defendants with TBI. Many of the public defenders who participated in this survey lacked the training related to the criminal justice and legal aspects of TBI. For example, there was a distinct difference in reporting by public defenders on the symptoms of mild and moderate forms of TBI. Buttressing this point, very few public defenders referred clients who might have TBI for assessment and treatment services. Despite this limited familiarity with TBI, public defenders reported being overwhelming receptive when training was provided. This advanced training is merited because TBI has a prevalence rate of $60 \%$ in adults and $30 \%$ in adolescents in correctional institutions [18-23]. As such, it is very likely that public defenders will frequently come into contact with defendants with TBI. Even in this study, public defenders reported that over half of their clients likely had TBI. In light of these findings, there is a strong need to develop and market advanced education and training programs on TBI in the legal system to public defenders.

\section{References}

1. Centers for Disease Control and Prevention (2013) Traumatic Brain Injury and Concussion.

2. Feigin VL, Theadom A, Barker-Collo S, Starkey NJ, McPherson K, et al. (2013) Incidence of traumatic brain injury in New Zealand: A population-based study. Lancet Neurol 12: 53-64.

3. Mouzon BC, Bachmeier C, Ferro A, Ojo JO, Crynen G, et al. (2014) Chronic neuropathological and neurobehavioral changes in a repetitive mild traumatic brain injury model. Ann Neurol 75: 241-254.

4. Ponsford JL, Downing MG, Olver J, Ponsford M, Acher R, et al. (2014) Longitudinal follow-up of patients with traumatic brain injury: Outcome at two, five, and ten years post-injury. J Neurotrauma 31: 64-77.

5. Levine B, Black SE, Cheung G, Campbell A, O'Toole C, et al. (2005) Gambling task performance in traumatic brain injury: Relationships to injury severity, atrophy, lesion location, and cognitive and psychosocial outcome. Cogn Behav Neurol 18: 45-54.

6. McCauley SR, Wilde EA, Miller ER, Frisby ML, Garza HM, et al. (2013) Preinjury resilience and mood as predictors of early outcome following mild traumatic brain injury. J Neurotrauma 30: 642-652.

7. Rao V, Lyketsos C (2000) Neuropsychiatric sequelae of traumatic brain injury. Psychosomatics 41: 95-103.

8. Santoro J, Spiers M (1994) Social cognitive factors in brain injuryassociated personality change. Brain Inj 8: 265-276.

9. Schönberger M, Ponsford J, Gould KR, Johnston L (2011) The temporal relationship between depression, anxiety, and functional status after traumatic brain injury: A cross lagged analysis. J Int Neuropsychol Soc 17: 781-787.

10. Wassenberg R, Max JE, Lindgren SD, Schatz A (2004) Sustained attention in children and adolescents after traumatic brain injury: Relation to severity of injury, adaptive functioning, ADHD and social background. Brain Inj 18: 751-764.

11. Gordon W, Brown M (2008) Mild traumatic brain injury: Identification, the key to preventing social failure. Brain Injury 5: 8-12.

12. Langlois JA, Rutland-Brown W, Wald MM (2006) The epidemiology and impact of traumatic brain injury: a brief overview. J Head Trauma Rehabil 21: 75-378.

13. DeKosky S, Ikonomovic M, Gandy S (2010) Traumatic brain injuryFootball, warfare, and long-term effects. N Engl J Med 363: 1293-1296.

14. Zaloshnja E, Miller T, Langlois JA, Selassie AW (2008) Prevalence of longterm disability from traumatic brain injury in the civilian population of the United States, 2005. J Head Trauma Rehabil 23: 394-400.

15. Centers for Disease Control and Prevention (2014) Injury prevention \& control: Traumatic brain, United States.

16. Williams WH, Mewse AJ, Tonks J, Mills S, Burgess CNW, et al. (2010) Traumatic brain injury in a prison population: Prevalence and risk for reoffending. Brain Inj 24: 1184-1188.

17. Shiroma EJ, Ferguson PL, Pickelsimer EE (2010) Prevalence of traumatic brain injury in an offender population: A meta-analysis. J Correct Health Care 16: $\quad 147-159$

18. Bamfield T, Leathern J (1998) Incidence and outcomes of traumatic brain injury and substance abuse in a New Zealand prison population. Brain Inj 12: $455-466.3$

19. Bogner J, Corrigan J (2009) Reliability and predictive validity of the Ohio State University TBI Identification Method with prisoners. J Head Trauma Rehabil 24: 279-291.

20. Diamond P, Harzke A, Magaletta P, Cummins A, Frankowski R (2007) Screening for traumatic brain injury in an offender sample: A first look at 
Citation: Brown J, Louie JP (2017) Perceptions of Traumatic Brain Injury among Public Defenders in the State of Minnesota . J Forensic Res 8: 383. doi:10.4172/2157-7145.1000383

Page 6 of 6

the reliability and validity of the traumatic brain injury questionnaire. J Head Trauma Rehabil 22: 330-338.

21. Morrell RF, Merbitz CT, Jain S, Jain S (1998) Traumatic brain injury in prisoners. J Offender Rehabil 27: 1-8.

22. Schofield, Butler PW, Hollis TG, Smith SJ, Lee NE, et al. (2006) Traumatic brain injury among Australian prisoners: Rates, recurrence and sequelae. Brain Inj 20: 499-506.

23. Slaughter B, Fann JR, Ehde D (2003) Traumatic brain injury in a county jail population: Prevalence, neuropsychological functioning and psychiatric disorders. Brain Inj 17: 731-741.

24. Farrer TJ, Frost RB, Hedges DW (2013) Prevalence of traumatic brain injury in juvenile offenders: A meta-analysis. Child Neuropsychol 19: 225-234.

25. Cebulla I (2016) The impact of neurocognitive deficits associated with traumatic brain injury on executive functions, mental health, and recidivism among male and female juvenile offenders: Doctoral dissertation, Alliant International University, San Diego, California.

26. Jaffee MS, Stokes JW, Leal FO (2007) Posttraumatic stress disorder and posttraumatic stress disorder-like symptoms and mild traumatic brain injury. J Rehabil Res Dev 44: 895-920.

27. Perron BE, Howard MO (2008) Prevalence and correlates of traumatic brain injury among delinquent youths. Crim Behav Ment Health 18: 243-255.

28. Colantonio A, Stamenova V, Abramowitz C, Clarke D, Christensen B (2007) Brain injury in a forensic psychiatry population. Brain injury 21: 1353-1360.

29. McLachlan K, Roesch R, Viljoen JL, Douglas KS (2014) Evaluating the psycholegal abilities of young offenders with fetal alcohol spectrum disorder. Law Hum Behav 38: 10-22. 